\title{
Un Frente de Trabajadores comandado por la clase obrera: El Partido Socialista Popular y las definiciones iniciales en torno a la política del Frente de Trabajadores, 1946 - 1957
}

\author{
A Workers Front led by the working class: \\ The Socialist Popular Party and the initial definitions of the thesis \\ Workers Front, 1946 - 1957
}

Pablo Garrido González*

\begin{abstract}
Resumen: La línea del Frente de Trabajadores (FT) sancionada por el Partido Socialista Popular (PSP) en 1955 es un hecho determinante en la trayectoria política de la izquierda chilena hasta 1973, la cual ha sido objeto de escasa atención por parte de la historiografía dedicada al estudio de los partidos de izquierda del periodo. Este trabajo pretende desde la historia del pensamiento político examinar la trayectoria ideológica y las definiciones iniciales del FT socialista, poniendo especial énfasis en el proceso de definición ideológica y teórica al interior del socialismo popular, el cual permite y explica la adopción de dicha línea política.
\end{abstract}

Palabras clave: Frente de Trabajadores; Partido Socialista Popular; Socialismo chileno; Ideología.

\begin{abstract}
The Front Workers line (FT) sanctioned by the Popular Socialist Party (PSP) in 1955 is a determining factor in the political course of the Chilean left until 1973, which has received limited attention from historiography who studies the left in this period. This work aims from the history of political thought examine the ideological trajectory and initial definitions of socialist FT, emphasis on the process of ideological and theoretical definition into the socialism that allows the adoption of that line.
\end{abstract}

Keywords: Workers Front; Popular Socialist Party; Chilean socialism; Ideology.

Recibido: 27 octubre 2016

Aceptado: 6 marzo 2017

\footnotetext{
* Chileno, Politólogo UDP, (C) Magister en Historia USACH, Investigador asociado programa historia de las ideas políticas en Chile - Universidad Diego Portales
} 


\section{Introducción}

El presente trabajo tiene por finalidad caracterizar la discusión política e ideológica del Partido Socialista Popular (PSP) en torno a la línea estratégica del Frente de Trabajadores. Para ello, se pretende revisar fuentes partidarias claves, publicaciones y discusiones parlamentarias que den cuenta de la trayectoria ideológica y política inicial de la tesis socialista, considerando para tales efectos el periodo comprendido entre 1946 y 1957. El periodo antes mencionado, está caracterizado por una agudización del conflicto al interior del partido durante la década del 40 , el cual está marcado por la crítica de las experiencias colaboracionistas tras la participación socialista en el Frente Popular, la colaboración del PSP con el gobierno del General Carlos Ibáñez del Campo en 1953, y -paralelamente- el proceso de acercamiento con otras fuerzas de izquierda que culminó con la formación del Frente de Acción Popular (FRAP) en 1956 y la unificación socialista al año siguiente. Estos aparecen como momentos en los cuales el socialismo chileno propone y define la línea estratégica del Frente de Trabajadores como forma de afrontar la disputa por el poder, a modo de síntesis de la experiencia social y política previa. De esta forma, este trabajo propone que las definiciones teóricas y políticas de la línea estratégica socialista son resultado de las experiencias acumuladas por el socialismo chileno en sus diversas etapas de colaboración con coaliciones políticas más amplias durante las décadas de 1940 y 1950. Para desarrollar lo anterior, la selección de fuentes consideró documentos que dan cuenta de las verbalizaciones y discursos oficiales al interior del PSP, es decir, aquellos documentos, mensajes, declaraciones, boletines, folletos y revistas difundidos como voz, oficial del Partido Socialista Popular, así como aquellas publicaciones y registros de las instancias oficiales del mismo, tales como congresos, plenos, declaraciones de la directiva, etc.

El periodo que comprende este artículo es materia de debate dentro de la historiografía disponible sobre el desarrollo del socialismo chileno, en este sentido es que resalta la lectura de Paul Drake quien en su trabajo Socialismo y populismo en Chile ${ }^{1}$ postula que el fin de la participación socialista en el gobierno de Ibáñez dio paso a la radicalización programática de la izquierda y el ascenso de las posiciones marxistas en desmedro del populismo que había caracterizado la etapa anterior del socialismo chileno, dando pie a la "tragedia del socialismo y del populismo". Por otra parte, los trabajos de Benny Pollack ${ }^{2}$ denominan este periodo del socialismo chileno como "la fase de la ideología", la cual estaría caracterizada por el constante debate interno y el desarrollo de una línea estratégica clasista, que excluía cualquier forma de colaboración con los partidos de centro, en particular con radicales o falangistas. Sin embargo, y pese al aparente endurecimiento de la línea política del Partido Socialista Popular desde su salida del gobierno de Carlos Ibáñez,

\footnotetext{
${ }^{1}$ Paul Drake, Socialismo y Populismo. Chile 1936-1973, Instituto de Historia Universidad Católica de Valparaíso, 1992.

${ }^{2}$ Esta propuesta está desarrollada en: Benny Pollack, "The Chilean Socialist Party: Prolegomena to its Ideology and Organization", Journal of Latin American Studies 79:1, 1978. Y, en: Benny Pollack y Herman Rosenkrantz, Revolutionary Social Democracy: The Chilean Socialist Party, London, Pinter, 1986.
} 
este es también el periodo de acercamiento y diálogo con otras fuerzas políticas de izquierda, proceso que culmina con la formación del FRAP en 1956, mediante la alianza del todavía ilegalizado Partido Comunista, la facción del Partido Socialista de Chile liderada por Salvador Allende y los Socialistas Populares de Raúl Ampuero y Clodomiro Almeyda.

Sin embargo, y si bien el periodo que comprende este trabajo está cruzado por el debate al interior del PSP, también lo está por la inventiva teórica del socialismo chileno, la cual se refleja en las discusiones y diagnósticos propios que terminan con la adopción de la línea del Frente de Trabajadores, y la decisión estratégica de participar en alianzas políticas de corte clasista. La opción de una política de clase que se niega al colaboracionismo con el centro político o a la participación en coaliciones "multiclasistas" es una constante dentro del socialismo chileno. Como lo observan Casanueva y Fernández en el trabajo El Partido Socialista y la lucha de clases en Chile $^{3}$, la tesis del Frente de Trabajadores, en tanto tendencia que proponía una alianza formada exclusivamente por los partidos representantes de las clases populares, es una constante en el desarrollo histórico del partido que tiene su primera expresión de importancia en la facción crítica a la política del Frente Popular durante la década del 40, expresada por los denominados "inconformistas" que a la postre fundaron el Partido Socialista de los Trabajadores (PST).

Considerando lo anterior, este trabajo entiende que la formación de la línea estratégica del Frente de Trabajadores es producto del desarrollo de una trayectoria ideológica particular dentro del socialismo chileno, que tiene durante su desarrollo histórico la presencia constante de tendencias que defienden la opción de la alianza clasista, las cuales se cristalizan en primer lugar, en un diagnóstico particular sobre la realidad política y social chilena para luego dar paso a una estrategia y línea política propiamente tal a partir de 1955, cuando el XVI Congreso General del PSP proclame su beligerancia contra los partidos centristas y la movilización popular sostenida para acabar con el sistema capitalista $^{4}$. Como observa Luis Ortega ${ }^{5}$, si bien este es el congreso en donde el partido decide apartarse de lo que había sido la "política socialista" de alianzas hasta ese momento, el proceso de radicalización de la línea socialista tiene sus raíces en la crisis partidaria de la década del 40 y un correlato con la profunda crisis económica y política de la década de 1950.

En términos teóricos, este trabajo asume la perspectiva de la historia del pensamiento político. En este aspecto, se entiende que las verbalizaciones de los actores tienen determinadas intenciones, de esta forma los actos de habla son también acciones, en tanto lo que se pretende dilucidar, además de lo que determinado actor está diciendo, es también

\footnotetext{
${ }^{3}$ Fernando Casanueva y Manuel Fernández, El Partido Socialista y la lucha de clases en Chile, Santiago, Quimantu, 1973.

4 Julio Cesar Jober, El Socialismo chileno a través de sus congresos, Santiago, Editorial Prensa Latinoamericana, 1965. p.77

${ }^{5}$ Luis Ortega, "La radicalización de los socialistas de Chile en la década de 1960", Universum 2008, 23:2, 2008. 152-164.
} 
entender que es lo que está intencionadamente haciendo (ya sea responder, emplazar, definir, convocar, ironizar o diferenciarse respecto de otros) cuando escribe o verbaliza determinados mensajes ${ }^{6}$. Así mismo, desde esta perspectiva es fundamental entender que los mensajes y verbalizaciones de los actores sólo toman sentido en función de un lenguaje común y compartido, que limita aquello que puede ser dicho o comprendido por quienes cohabitan en un mismo escenario histórico, lingüístico y de significados.

Sin perjuicio de lo anterior, para estos efectos, el lenguaje además de ser una estructura de poder compartido, en tanto determina los significados disponibles en un momento histórico particular, no puede ser monopolizado puesto que, es esencialmente disputable y contestable $^{7}$. Esto implica considerar que las discusiones y debates del socialismo chileno se enmarcan dentro de un proceso de formalización y conceptualización de un lenguaje que da forma a una línea política particular, la que se expresa de manera más o menos formalizada y conceptualizada en la trayectoria ideológica del Frente de Trabajadores. Como menciona J.G.A. Pocock:

En toda comunidad política cabe encontrar diversos vocabularios conceptuales, estilos de discurso o formas de pensamiento a distintos niveles de formalización. Los miembros de esa sociedad recurren a ellos para expresar, de un modo eminentemente formal, lo necesario para formar parte de la vida política. Se trata de lenguajes que proceden de las fuentes más diversas (...) y su contenido varía de forma implícita y explícita. Podemos demostrar que todo lenguaje político consta de muchas afirmaciones y tiene más implicaciones de las que cabe deducir en un momento concreto. Y una parte significativa de lo que denominamos teoría política no se ocupa tanto de construir una teoría de la política coherente, sino de intentar reconstruir y explorar las implicaciones que tuvo ese lenguaje particulado al utilizarse para el debate político, la acción y la elección.

Considerando lo anterior, y contrariamente a lo propuesto por Paul Drake, este trabajo propone que el periodo de definiciones iniciales en torno a la cuestión de la línea estratégica es más que "la tragedia del populismo y del socialismo". De esta forma, se considera que el periodo antes mencionado está caracterizado por la discusión y el debate en términos ideológicos y políticos, siendo determinante para el desarrollo de la política del PSP y posteriormente del socialismo ya unificado a partir de 1957. En este aspecto, se considera que la crítica inicial a la experiencia de los frentes populares es el punto de partida para el desarrollo de discusiones, debates y reflexiones en el campo ideológico y político que decantan en la adopción de una línea estratégica particular, la cual en ningún

\footnotetext{
${ }^{6}$ Quentin Skinner, "Language and political change”, T. Ball, J. Farr, \& R. L. Hanson (Eds.), Ideas in context: political innovation and conceptual change, Melbourne, Cambridge university press, 1995, 6-23.

${ }^{7}$ William E. Connolly, The Terms of Political Discourse. Nueva Jersey, Princeton University Press, 1993.

${ }^{8}$ JGA. Pocock, Pensamiento político e historia: Ensayos sobre teoría y método, Madrid, Ediciones Akal, 2009.p 41.
} 
caso termina de definirse (o formalizarse, siguiendo a Pocock) completamente con la formación del Frente de Acción Popular en 1956 ni con la unificación del socialismo en 1957. Dicho de otro modo, la línea estratégica del Frente de Trabajadores obedece a las lecturas sobre la experiencia del socialismo chileno en gobiernos de colaboración de con partidos burgueses, siendo periodos determinantes en la posterior elaboración de una línea política particular y propiamente socialista, que niega el rol transformador y progresivo de las burguesías nacionales, proponiendo una estrategia que privilegie la movilización social y promueva la alianza exclusiva de los partidos populares o de avanzada. En este aspecto, la línea del FT posee diferencias sustanciales tanto en lo político como en lo ideológico con la línea del Frente de Liberación Nacional comunista, las cuales superan con creces lo meramente conceptual ${ }^{9}$.

\section{Crisis y transformación del socialismo chileno}

El PSCh está fundado sobre una base paradojal, donde confluyen desde sus inicios tendencias y tesis políticas provenientes desde una diversidad de corrientes marxistas, nacionalistas, desarrollistas, populistas, e incluso anarco-sindicalistas. Esta diversidad fue motivo de debates y discusiones que de alguna u otra forma son las responsables del desarrollo ideológico y político del socialismo chileno, dándole una riqueza y densidad única para la política del siglo XX chileno. Sin embargo, en esta diversidad de posiciones esta la razón primera de los problemas orgánicos de la organización. Divisiones, escisiones, expulsiones y la manifestación violenta, mas no siempre la resolución de conflictos internos, son características del desarrollo histórico y de la trayectoria ideológica del partido. En este sentido es que el desarrollo de la línea estratégica del socialismo chileno no está exenta de estas lógicas. La diversidad ideológica, de lecturas y de diagnósticos sobre la realidad nacional e internacional está constantemente tensionando las relaciones al interior del partido, y de este con la institucionalidad, sus bases y con el resto del sistema político chileno.

La primera manifestación considerable de una opción clasista se da en pleno periodo de los Frentes Populares, lo que partió como una facción "inconformista" al interior del PSCh liderada por Cesar Godoy Urrutia, Natalio Berman y Emilio Zapata termina por escindirse del partido, formando en 1940 el Partido Socialista de los Trabajadores (PST). Si bien la opción de los entonces diputados socialistas termina en 1944 con el ingreso de la mayoría de sus militantes al Partido Comunista, la experiencia fue una de las primeras escisiones de importancia a nivel nacional de la estructura partidaria, la cual tenía su principal motivo en la relación del partido con la institucionalidad y su posibilidad de construir un gobierno para las masas desde el colaboracionismo. No alcanzarán a pasar cuatro años para que el socialismo viva un nuevo conflicto, el mismo año en que se disuelve el PST y en plena realización del X Congreso General Ordinario del partido, el líder histórico y, hasta

\footnotetext{
${ }^{9}$ Marcelo Casals, El alba de una revolución. La izquierda y la construcción estratégica de la "vía chilena al socialismo". 1956-1970, Santiago, Lom, 2010, p. 51
} 
entonces máxima figura del socialismo, Marmaduque Grove, realiza un congreso paralelo que termina en la fundación del Partido Socialista Auténtico (PSA).

En la lectura de los inconformistas, el socialismo había perdido su rigidez doctrinaria y extraviado la inspiración inicial para la cual ingresó a colaborar en el Frente Popular: la instauración del socialismo. Desde este punto de vista, los socialistas liderados por Cesar Godoy, reclamaban que el inconformismo, más que un estado de ánimo o doctrina particular, no es más que el rescate de las tradiciones de lucha del socialismo y del movimiento obrero, las cuales habrían sido abandonadas para dar paso a la defensa de los intereses mezquinos de algunos grupos dirigentes del partido ${ }^{10}$. Representantes de la tendencia que propuso abstenerse de participar en ministerios durante el gobierno de Pedro Aguirre Cerda en el V Congreso General del PSCh, son expulsados tras el VI Congreso, acusando a Godoy de traidor y arrastrando con su salida a un importante número de militantes, sobre todo de la organización juvenil del partido ${ }^{11}$. La tensión entre socialistas inconformistas y socialistas oficiales no es más que el enfrentamiento entre quienes proponen la moderación y la negociación con el resto del Frente Popular en el ejercicio ministerial y quienes ven la entrada del partido en el gobierno como el momento propicio para iniciar cambios de mayor alcance y profundidad.

Las tensiones entre oficialistas e inconformistas se hacen insostenibles el año 1939 cuando el diputado socialista y dirigente campesino Emilio Zapata, sufre un revés por parte del gobierno al promover los derechos de sindicalización para los "obreros del campo", lo cual es desechado por el mismo gobierno, quien nombra una comisión especial para estudiar el caso y posibles ilegalidades conforme el código del trabajo vigente. La comisión se forma tras las quejas formuladas a los intentos de sindicalización campesina y presionada por la Sociedad Nacional de Agricultura. En palabras de Zapata no es posible que el gobierno "permita la campaña de los personeros, que ayer se asociaron al pirata, me refiero al candidato nacional a la Presidencia de la República, como fue el señor Gustavo Ross y que formaron tan fuerte resistencia contra el candidato del Frente Popular y hoy recurren a él para suprimir un derecho inalienable e irrenunciable de los trabajadores del campo" ${ }^{12}$. A lo anterior, se suma el asesinato a tiros del dirigente de la construcción, miembro del comité central e inconformista Pablo López Cáceres por militantes de las milicias socialistas en un local del partido tras algunos incidentes entre ambas facciones ocurridas luego de la realización del VI Congreso en el mes de diciembre de ese año.

El VI Congreso ordinario del PS, en su cuenta general intenta hacer un repaso detallado de la acción del partido dentro del gobierno, recalcando el papel del socialismo en la contención del Ibañismo, de las maniobras centristas o derechistas organizadas por los sectores más conservadores del Partido Radical y respondiendo de manera directa a la

\footnotetext{
${ }^{10}$ Cesar Godoy, ¿Qué es el inconformismo?, Santiago, Editorial Combate, 1940.

${ }^{11}$ Corkill, David, "The Chilean Socialist Party and the Popular Front. 1933-1941”, Journal of Contemporany History, 11:2/3, julio 1976, 261-273

${ }^{12}$ Diario de Sesiones de la Cámara de Diputados, Sesión 19 extraordinaria, en 19 de abril de 1939.
} 
crítica del inconformismo al sostener que "Si bien es cierto que este gobierno no ha realizado hasta ahora las más urgentes reivindicaciones del programa de izquierda ni ha planificado la solución de los problemas de mayor envergadura, la verdad es también, que ha sido nuestro Partido el que más ha luchado por impulsar el cumplimiento de esas realizaciones $\mathrm{Si}$ no ha tenido éxito para vencer las resistencias de la derecha y las dificultades planteadas por sectores de izquierda, hay que reconocer que ha sido el único que ha formulado públicamente soluciones concretas, en vez de limitarse a hacer críticas negativas que no aportan elementos constructivos a los gobernantes" ${ }^{13}$.

Para tratar de apaciguar los ánimos y las divisiones en el transcurso del congreso, el comité central propone la revisión del plan de acción inmediata en el gobierno. Sin embargo, la intención de la facción inconformista es llegar al comité central con Cesar Godoy a la cabeza para cambiar la dirección del partido frente al gobierno, opción que es derrotada por 165 votos frente a 201. Tras esto, en abril de 1940 Godoy y la facción inconformista son expulsados del partido. Mientras el comité central titulaba "el inconformismo: pretexto para el divisionismo y la traición" "14 el propio Godoy una vez sabida la sentencia del tribunal del partido, cerraba una larga intervención realizada en la Cámara de Diputados diciendo que el inconformismo "no es otra cosa que un movimiento de depuración (...) no es otra cosa que el impulso doctrinario para recuperarlo (al socialismo) y ponerlo otra vez, auténticamente, al servicio de los trabajadores de todo Chile para que se devuelva a este Partido el prestigio y la autoridad moral que nunca debió haber perdido" 15

Lo interesante de esta pugna, desde el punto de vista propuesto por este trabajo, es la disputa a nivel teórico. El socialismo chileno hasta su entrada en el Frente Popular no tenía un cuerpo doctrinario desarrollado y uniforme sobre el cual orientar la acción política del partido, lo cual se sumaba a las dinámicas inherentes a la estructura misma de la organización. De esta forma, el inconformismo además de ser una corriente de opinión al interior del PS también es reflejo de los liderazgos caudillistas, el ejercicio autoritario de las jerarquías partidarias y sobre todo de la indefinición doctrinaria que no sería resuelta hasta 1947. Lo anterior deja espacio para la revisión, la interpretación y el disenso con el escaso desarrollo teórico e ideológico del partido que, a esa fecha, no había variado sustancialmente sus posiciones respecto de las consignas con que se fundó en 1933.

La respuesta del Partido ante las divisiones toma forma en una serie de documentos que intentan clarificar la acción del socialismo en el gobierno. Por ejemplo, en un manifiesto publicado en enero de 1940, sólo un mes después del VI Congreso, el PS trata de mostrarse unificado y coherente al proponer una nueva orientación de la política económica del gobierno la cual debiera avanzar en temas de colonización agrícola, probidad administrativa, la creación de empresas productivas nacionales y la nacionalización de

\footnotetext{
${ }^{13} \mathrm{PS}$, El Partido Socialista y su $6^{\circ}$ Congreso Ordinario, Talleres Gráficos Gutenberg, 1940, pp. 9-10

${ }^{14}$ Barricada, $\mathrm{N}^{\circ} 14$, abril de 1940

${ }^{15}$ Diario de sesiones de la Cámara de Diputados, Segunda Sesión Extraordinaria en 21 de abril de 1940.
} 
recursos básicos. Señalando respecto de su actitud frente al gobierno y a las acusaciones de "falta de dinamismo" en la acción ministerial que:

Los partidos populares tienen el deber de orientar a las masas y no pueden incurrir en el error suicida de perturbar su criterio con perspectivas irrealizables o utópicas, que a la primera derrota conducen fatalmente al desaliento y a la desmoralización colectiva. Por eso hemos afirmado ante la masa que en el actual gobierno y en las actuales circunstancias nuestro partido no podría plantear soluciones socialistas a los problemas, a pesar de que en nuestro concepto, son las únicas que tienen carácter duradero, porque encaran nuestros males sociales con el justo criterio de conquistar el bienestar económico y la liberación de nuestras clases trabajadoras. ${ }^{16}$

Pese a estos intentos por controlar el faccionalismo y las querellas internas, aparecen nuevos problemas, como la desmejorada relación con el Partido Comunista ${ }^{17}$, la constante rotativa ministerial y el desgaste de relaciones con el Partido Radical durante el gobierno de Juan Antonio Ríos, Presidente de la Republica tras la muerte de Pedro Aguirre Cerda. Sin embargo, la tensión entre las fracciones que deseaban la colaboración y aquellas que promovían el fin de esta continuará. En 1945 y tras la realización del X Congreso, que declara el fracaso socialista en la gestión gubernativa, y en medio de una crisis orgánica y partidaria severa, se propone la realización de un congreso general extraordinario con miras a poner fin a las turbulencias al interior del partido. Se define una postura de independencia total respecto del gobierno, del Partido Comunista y del "resto de la reacción" en una tesis definida como Tercer Frente.

En este contexto, y pese a los intentos por tomar una posición clara que logre mantener la unidad interna, el PSCh se encontraba en un periodo de retroceso innegable: sólo en términos electorales el partido pasó de 15 diputados en 1941 a 6 en 1945, bajando en poco más del $50 \%$ su volumen electoral en el periodo antes señalado. Por si fuera poco, ante la elección presidencial de 1946 el diputado socialista y máxima figura del partido en el ambiente sindical, Bernardo Ibáñez, solo logra el 2,54\% de los votos para suceder al fallecido Juan Antonio Ríos, logrando obtener más de mil votos sólo en la ciudad de Santiago.

Durante ese mismo año, y con el peso del fracaso electoral a cuestas, se realiza el XI Congreso General Ordinario. El partido vuelve a presentarse dividido en dos posiciones: la tercer frentista liderada por Bernardo Ibáñez y una oposición revolucionaria, liderada por Raúl Ampuero. La facción Ampuerista termina imponiéndose y materializando sus pretensiones de transformar programáticamente el partido, elaborando un voto político que

${ }^{16}$ PS, Manifiesto que dirige el Partido Socialista al país, Santiago, Editorial Cultura, enero de 1940, p.6

${ }^{17}$ El PS acusaría que tras la firma del pacto nazi soviético la III internacional ordena el fin de los Frentes Populares, iniciándose una serie de desencuentros al interior del Frente Popular en Chile. La propuesta de los socialistas fue la reagrupación de un bloque democrático que excluyera al PCCh lo cual fue negado por los Radicales, aislando al PS en las elecciones legislativas de 1941. 
reafirma el contenido revolucionario y de clase del socialismo, manifestando una posición de independencia frente al gobierno de González y los demás partidos de izquierda. Este es el congreso del inicio de la transformación del partido, en él se elige como secretario general a Raúl Ampuero -de entonces 29 años- y como miembros del comité central asumen militantes como Oscar Waiss y Eugenio González, quienes serán fundamentales en la discusión política interna de aquí en adelante.

La línea política definida por este congreso, pese a afirmar la independencia del partido frente al gobierno, declara abiertamente su simpatía con el programa que llevó a la presidencia a González. Sin embargo, el PS manifiesta claramente su desconfianza frente a un gabinete de unidad nacional que consideraba "una primera amenaza contra el fiel cumplimiento del programa que se ha ofrecido a la opinión pública", y agregaba que, "La experiencia nos ha demostrado de un modo fehaciente que estas combinaciones híbridas, de intereses contradictorios, no resultan adecuadas para aplicar una política renovadora, conducen a sucesivas capitulaciones y por último, a una total infecundidad"18.

En la misma línea, el pleno nacional del partido complementa la tesis de la independencia, y juzgando en duros términos la política adoptada por el socialismo en el periodo anterior Ampuero escribía: "La misión revolucionaria del Socialismo no permite su incorporación definitiva al juego intrascendente y rutinario de la política burguesa. Si a veces, por un superior imperativo de las circunstancias o por una equivocada valoración de las coyunturas históricas, el Partido Socialista ha comprometido su finalidad específica en colaboraciones temporales, es hora de que rectifique su conducta y se apreste a cumplir su trascendental destino de clase" 19

Sin embargo, la resolución más importante de este congreso respecto a la definición de una línea política y a nivel ideológico, es la realización de una conferencia nacional programática en el año 1947 a cargo de Eugenio González y de Salvador Allende. El programa además de fijar la línea política y sus directrices principales, tiene el gran mérito de rescatar en sus fundamentos teóricos las particularidades de la discusión ideológica socialista, fijando la independencia respecto de la izquierda soviética y comunista, pero rescatando también la posibilidad creadora del partido en cuanto a discusión teórica y política refiere, en este aspecto, y bajo el título "El movimiento histórico y la lucha de clases", postula:

La doctrina socialista no es un conjunto de dogmas estáticos, sino una concepción viva, esencialmente dinámica, que expresa en el orden de las ideas políticas las tendencias creadoras del proletariado moderno. Producto de una situación histórica definida, ella se ha ceñido en su desarrollo al ritmo del movimiento social, enriqueciéndose de continuo con la experiencia de lucha de la clase trabajadora.

18 "El Partido Socialista mantiene su tradicional beligerancia Anti-Reaccionaria”, Espartaco, №1, marzo-abril de 1947, pp. 36-37.

19 "La etapa de recuperación del P. Socialista se ha cumplido", Espartaco, N 2-3, julio de 1947, p.59 
El socialismo no formula principios absolutos, de abstracta validez universal, ni se afirma tampoco en un concepto metafísico, y por lo mismo intemporal, de la naturaleza humana; parte de una consideración realista del hombre concreto, sujeto de necesidades siempre cambiantes y portador de valores siempre relativos, del hombre histórico y social que crea las condiciones objetivas de su propia vida y va siendo, a la vez, condicionado por ellas en el proceso de la existencia. ${ }^{20}$

Esta posibilidad está dada en parte por el rechazo tajante a cualquier adscripción internacional que no sea estrictamente nacionalista y latinoamericana, como modo de rescatar las particularidades del proceso social, político y económico del continente y especialmente de la realidad chilena. De esta postura inicial, aparece el segundo punto doctrinario de importancia para el posterior desarrollo de las discusiones teóricas dentro del partido. En este sentido, el diagnostico que hace el socialismo sobre la realidad del espacio latinoamericano y chileno caracteriza la inmadurez social de las clases trabajadoras del continente, las cuales no han logrado los niveles de movilización y conciencia necesarios producto de la mantención de un régimen semi-colonial, del cual la burguesía no sólo se beneficia, sino que además es impotente de transformar por encontrarse "social y psicológicamente" retrasadas respecto del desarrollo económico. Por esta razón "corresponde en el momento actual a los partidos socialistas y afines de América Latina llevar a término en nuestros países semi coloniales las realizaciones económicas y los cambios jurídicos que en otras partes ha impulsado la burguesía",21

Pese al recambio generacional en la dirigencia del socialismo y de las nuevas definiciones teóricas, políticas y programáticas, el partido sufre una última gran escisión durante su XII Congreso General Ordinario en 1948. La facción derrotada en el congreso anterior liderada por Bernardo Ibáñez y Juan Bautista Rossetti, desconociendo la posición del partido frente a la ley de defensa permanente de la democracia propuesta por el presidente González vota en favor de la misma. Como consecuencia, el tribunal del Partido reacciona y termina por decretar la expulsión de ambos. La facción expulsada, con la venia del ejecutivo y mediante un fallo del registro electoral se queda con el nombre del Partido Socialista de Chile para afrontar las elecciones parlamentarias de 1949, la facción mayoritaria y que logra retener al grueso de la militancia adquiere el nombre de Partido Socialista Popular.

La nueva escisión se refleja en la misma discusión de la ley de defensa permanente de la democracia. El diputado y jefe de la brigada parlamentaria socialista, Astolfo Tapia, expresa el rechazo del Partido Socialista al proyecto por considerarlo "anti-obrero y antipopular", y agregando en clara alusión a la facción de Rosetti e Ibáñez que "El mismo Mussolini fue dirigente del Partido Socialista Italiano, y después fue el creador del fascismo, totalitario, opresor y brutal. Hitler se llamaba también socialista y fue, del mismo modo, creador de otro enfermizo engendro político y social que llevó a la ruina a Alemania

${ }^{20}$ Partido Socialista de Chile, "Fundamentación teórica", Por una democracia de trabajadores. Programa del Partido Socialista, Santiago, imprenta victoria, 1948, p.4

${ }^{21}$ Ibíd. p. 11

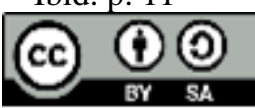


y a casi toda Europa"22. En la otra vereda, Luis González Olivares, diputado socialista y dirigente de la Confederación de Trabajadores de Chile por el Sindicato Tranviario de Santiago, expone sus preocupaciones sobre el proyecto. Representa al sector de la CTCh que está a favor de la proscripción del Partido Comunista, por considerarlo "la quinta columna del soviet totalitario en nuestro país" pero preocupado por estimar que el proyecto de defensa permanente de la democracia "adolece del defecto de no circunscribirse exclusivamente al Partido Comunista, sino que llega hasta las propias organizaciones gremiales, por el solo hecho que alguna vez estuvieron dirigidas por dicha secta internacional. La CTCh estima (...) que no deben confundirse al Partido Comunista con los instrumentos o herramientas de defensa del proletariado (...) porque jamás el Partido Comunista ha sido un instrumento de liberación de los obreros chilenos, sino simplemente una agencia política al servicio del imperialismo ruso."23

Pese a que durante el año 1949 se organizó un comité por la unidad del socialismo, el que llegó inclusive a tener un congreso con miras a resolver los desencuentros entre ambas corrientes, éste fracasó y volvió a poner en evidencia las diferencias tácticas, políticas e ideológicas. Según Jobet ${ }^{24}$ el fracaso se debe a la intransigencia de la facción en el gobierno para no abandonar sus cargos y la negativa del PSP de adherir a los oficialistas que concurrieron al mismo, incluso cuando el congreso elabora un voto político que termina con la participación de PSCh en el gobierno como condición previa para la unificación y se presenta una tesis política que, entre otras cosas, reafirmó la independencia del gobierno pero que sólo adhiere a los postulados sobre política internacional del programa de $1947^{25}$. Lo cierto es que el congreso de unidad se disuelve sin lograr la reunificación del socialismo chileno, exponiendo en un manifiesto final dirigido a la opinión pública la "profunda e insalvable discrepancia doctrinaria entre los elementos oficialistas, aferrados, a cualquier precio, a los Ministerios, y los que anhelamos independencia y dignidad para nuestro Partido. Estos dirigentes, con obstinación e intransigencia increíbles, se negaron a discutir cualquier fórmula que hubiese significado su retiro inmediato o mediato del Gobierno"26

La última escisión de importancia en este periodo es la adhesión en 1951 de la candidatura presidencial de Carlos Ibáñez del Campo durante el pleno nacional desarrollado en Valparaíso. Con este hecho, que venía configurándose desde el congreso general de 1950, se retiran del partido Tomás Chadwick y el senador Salvador Allende, formando un movimiento de recuperación socialista, que a la postre se uniría al PSCh formando el Frente Nacional del Pueblo (FRENAP) para afrontar, junto el proscrito Partido Comunista, las elecciones de 1952. La participación del PSP en el gobierno de Ibáñez fue corta y turbulenta, pero también beneficiosa en términos electorales. Bajo la consigna "un

\footnotetext{
${ }^{22}$ Diario de sesiones de la cámara de diputados, $6^{\circ}$ sesión extraordinaria en 12 de mayo de 1948.

${ }^{23}$ Ídem.

${ }^{24}$ Julio Cesar Jobet, El Partido Socialista de Chile Tomo I, Santiago, Ediciones Prensa Latinoamericana, 1971. p. 213

${ }^{25}$ Comité nacional de Unidad del Socialismo. "Unidad, doctrina y acción del socialismo" Santiago, impresora rosas, 1949. pp. 11-31

${ }^{26}$ Ibíd., p.36
} 
parlamento para Ibáñez" y pese a la salida de dos figuras importantes en el plano legislativo, el PSP logra en las parlamentarias de 195319 diputados y 4 senadores, transformándose en la segunda fuerza Ibañista en el parlamento tras el Partido Agrario Laborista.

Como señala el historiador Joaquín Fernández Abara ${ }^{27}$, el ibañismo representó una posibilidad de "resurrección" para el socialismo. Según el mismo trabajo, entre los motivos que explicarían la entrada del Socialismo Popular al movimiento Ibañista se pueden contar el interés de no seguir radicalmente aislados de la acción legislativa ante el retroceso electoral sostenido desde 1943; el aparente giro de Ibáñez hacía la izquierda reflejado en los sucesivos desencuentros entre el candidato y las facciones derechistas del Agrario Laborismo; y la intención de llevar adelante una política que acabara con las leyes represivas, aumentara el poder del estado y atacara algunas posiciones tradicionalmente dominadas por las elites en el campo de la economía. El PSP intento influir con éxito en el programa presidencial del movimiento ibañista, promoviendo un programa moderado que buscaba aumentar la movilización social y el poder del estado, lo cual también fue facilitado por el propio Carlos Ibáñez en su búsqueda de un acercamiento con la izquierda.

Sin embargo, esta influencia y los gestos del propio Ibáñez no fueron suficientes para evitar que la facción anti ibañista dentro del PSP terminará por escindirse, aduciendo el carácter fascistizante de la campaña y temiendo que se replicará parte de la acción represiva promovida por el peronismo argentino, del cual Ibáñez era seguidor confeso.

Lo cierto es que con la fundación del FRENAP y la constante declaración de independencia del PSP durante su participación en el gobierno de Ibáñez, las dos facciones del socialismo chileno ya configuran las posiciones que se reencontrarán y debatirán la conducción del Frente de Acción Popular en 1956. En este sentido, el programa del FRENAP es claro en mencionar la necesidad del re-establecimiento inmediato de las libertades democráticas, pero asumiendo que es un movimiento permanente y "llamado a unificar, con la clase obrera como espina dorsal, a los sectores más conscientes de la sociedad chilena: campesinos y agricultores progresistas; empleados, artesanos, maestros e intelectuales; profesionales, comerciantes e industriales con sentido nacional; mujeres y jóvenes dispuestos a producir en Chile un profundo cambio que, lo arranque del estado de atraso y de crisis en que se encuentra y lo impulse por el camino del progreso en todos los órdenes" 28

Por su parte, el PSP termina su irregular colaboración con el gobierno después de asumir labores ministeriales desde sus inicios en noviembre de 1952, las cuales abandonó en junio de 1953 declarando su colaboración desde una "independencia constructiva" con el gobierno, volviendo a fines de ese mismo mes a asumir labores ministeriales para terminar

\footnotetext{
27 Joaquín Fernández Abara, El ibañismo (1937-1952): un caso de populismo en la política chilena, Santiago, Instituto de Historia Universidad Católica de Chile, 2007.

28 "Programa del Frente del Pueblo", Diario de sesiones del senado, sesión 25 en 9 de septiembre de 1952.
} 
saliendo definitivamente tras el XV Congreso en octubre de ese mismo año. El diputado Alegre, informado a la cámara de diputados sobre el voto político adoptado en el congreso estimaba que la colaboración ministerial del socialismo popular se basaba en el "pleno restablecimiento de las libertades democráticas; deseábamos la derogación de la Ley de Defensa Permanente de la Democracia" y "que desde el gobierno se impulsará una nueva política económica que significara la defensa del poder adquisitivo de sueldos y salarios" además de "la revisión del trato de Chile con el capital extranjero"29. El PSP, desde este momento, vuelve a defender su independencia y la del movimiento popular para alcanzar el poder y construir la república democrática de trabajadores sobre la base de una organización revolucionaria y de clase, rescatando los principales fundamentos planteados en el programa de 1947 y la línea política sancionada durante el congreso de 1946.

\section{Hacia un Frente de Trabajadores}

La salida del gobierno por parte del PSP tiene la intención de rescatar el movimiento "amorfo y heterogéneo" que llevó a Ibáñez al poder. Entre las razones que se podrían contar para la salida está justamente la heterogeneidad de las bases de apoyo Ibañistas, las que al poco andar, se extendieron a los denominados "partidos históricos" como el Partido Radical. El PSP poseía algunos elementos programáticos que concordaban con el programa Ibañista, como la industrialización, la nacionalización de los recursos naturales y la derogación de la Ley de Defensa Permanente de la Democracia, pero no estuvo dispuesto a tolerar el viraje del gobierno hacia posiciones de derecha o de centro que incluían, en parte por su baja representación parlamentaria, a los partidos tradicionales contra los que se habían levantado. Ya en junio de 1953, cuando el PSP abandonaba las labores ministeriales se podía observar la molestia en este aspecto:

Nosotros no podemos aceptar que, por útiles razones parlamentarias, se olvide la significación histórica del 4 de Septiembre. y se trate ahora de buscar entendimiento con fuerzas políticas repudiables como son la derecha económica y el Partido Radical. Proceder en esa forma es recaer en los vicios de la politiquería rechazada en las urnas, y contra la cual se mantiene latente el odio de las masas.

En este sentido, deseamos ser perfectamente claros. Nada queremos con los partirlos llamados históricos, con sus hombres fracasados y con sus métodos políticos. Para nosotros la revolución chilena ha comenzado, y no buscaremos entendimiento sino con las fuerzas representativas de este poderoso sentimiento nacional. ${ }^{30}$

Para los socialistas populares, la idea de participar del gobierno Ibañista implicaba tratar de dar dirección al movimiento Septembrista que permitió el triunfo de Ibáñez en la elección

\footnotetext{
29 “Actualidad política - Acuerdos adoptados por el último congreso del Partido Socialista Popular”, Diario de sesiones de la cámara de diputados, $2^{\circ}$ sesión extraordinaria en martes 20 de octubre de 1953

30 "Posición política del Partido Socialista Popular", Diario de sesiones de la cámara de diputados, sesión 3 en martes 2 de junio de 1953
} 
de 1952, movimiento que era percibido en los diagnósticos hechos por el PSP como uno de carácter "informe y heterogéneo" pero con gran sentido "anti oligárquico y anti imperialista". La idea inicial era "superar la ola del ibañismo llevando a las masas más allá, fuera de la legalidad burguesa, por encima del parlamentarismo inoperante, hacia la revolución derivada del impulso inicial de un triunfo electoral que, por sí sólo, no bastaba ni podía bastar" ${ }^{\prime 3}$. Lo anterior fue logrado sólo en la medida que se logró influir en el programa presidencial sin gravitar demasiado en la labor ministerial, tempranamente interrumpida por los constantes desencuentros entre el PSP y el gobierno, y el temprano viraje del Presidente hacia los partidos tradicionales. Una vez terminada la colaboración con el gobierno aún rondaba la idea de reorganizar al socialismo popular en torno a las fuerzas Septembristas, en este sentido, es que el PSP junto a otras fuerzas que habían apoyado la candidatura de Ibáñez intentaron sin éxito la organización de una Alianza Popular que tan sólo duró unos meses. Así lo expresaba el XV Congreso de San Antonio:

Al retirarse del Gobierno, el Socialismo Popular expresa el anhelo de las grandes mayorías nacionales para llevar adelante una firme política antioligárquica y antiimperialista y está seguro de que su intención será comprendida por el resto de los partidos que apoyaron al señor Ibáñez y que expresaron este mismo deseo durante la campaña electoral. Esta finalidad esencial no será jamás olvidada por nuestro Partido, y es ella la que explica nuestra cooperación directa en el Gobierno, a la que ahora hemos puesto término. Para cumplirla, el Partido Socialista Popular hace un llamado a las fuerzas populares y nacionales que levantaron la postulación presidencial del señor Ibáñez, y a todos los partidos y grupos de orientación progresista, seguro de que el curso natural de los procesos sociales llevará muy pronto a los trabajadores a expresarse mayoritariamente en una República Democrática de Trabajadores, que construya las bases de un sistema socialista en que encuentren satisfacción las más puras aspiraciones de los obreros, campesinos, empleados y sectores modestos de la población. ${ }^{32}$

Pese a lo anterior, este también es un congreso que define algunas posiciones doctrinarias de importancia en el desarrollo de la línea ideológica y estratégica del socialismo, dándole continuidad al proceso iniciado en 1946. La cuenta rendida por Raúl Ampuero en dicho congreso expresa, entre otras cosas, un diagnóstico desde una lectura particular de la teoría marxista para la realidad chilena, hecho crucial para comprender las lecturas teóricas del PSP y la posterior adopción de la línea estratégica del Frente de Trabajadores. En este sentido, Ampuero en su cuenta niega el rol revolucionario de la clase burguesa, rechazando de plano cualquier alianza con partidos y grupos representantes de dicha clase:

(...) la burguesía no es, en nuestros países, una clase revolucionaria. Los son, en cambio, los trabajadores industriales y mineros, los campesinos, la

${ }^{31}$ Oscar Waiss, Nacionalismo y Socialismo en América Latina (2 edición), Buenos Aires, Iguazú, 1961. p. 143

${ }^{32}$ Julio Cesar Jobet, op. cit, p. 14

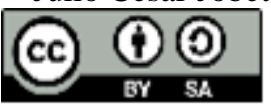


pequeña burguesía intelectual, los artesanos y operarios independientes, todos los sectores de la población cuyos intereses chocan con el orden establecido. $\mathrm{Y}$ en este conjunto, cada vez juega un papel más determinante la clase obrera. Por su organización, su experiencia sindical y política, su sentido de clase es el núcleo más resuelto de la lucha social.

Ahora bien, una clase que asume la misión históricamente abandonada por otra necesariamente le imprime sus propias características, le da un alcance de mayores proyecciones, le introduce modalidades propias de un estado más avanzado y radical. No puede tener la misma fisonomía ni igual contenido la revolución capitalista y burguesa realizada, bajo el mando de la burguesía, que si ella se desencadena y es conducida por los trabajadores, o más específicamente, por la clase obrera. ${ }^{33}$

En términos ideológicos y políticos lo interesante de esta afirmación es la constatación de una lectura particular que profundiza e implica una variación de las posiciones propuestas en 1946 y en el programa de 1947. En este aspecto, la posición de independencia propuesta a finales de la década del 40 venía acompañada de un diagnóstico que ponía énfasis en el retraso de la economía chilena, el problema de la inflación como causante de la desigualdad en la distribución del ingreso, pero por sobre todo, determinada por una posición que si bien declaraba independencia reconocía flexibilidad para actuar en conjunto con otras fuerzas políticas, incluso en bloques y frentes únicos, si esto iba en beneficio de los intereses programáticos del partido, tal y como sucedió con el gobierno de Ibáñez o algunas posiciones de colaboración parlamentaria con la Falange Nacional. En este sentido, el congreso de 1953 y el pleno del año siguiente terminan por acabar con la posibilidad de formar frentes únicos y bloques políticos con el resto de los partidos burgueses, propiciando en cambio las acciones comunes en el campo parlamentario o bien con la Central Única de Trabajadores en la forma de acuerdos transitorios e insistiendo constantemente en el carácter independiente del socialismo chileno frente a los partidos de centro y al centro de la izquierda.

El giro más marcado a esta política llega con la realización del XVI Congreso en 1955, en este aspecto se considera fracasado el llamado hecho durante el congreso anterior para reagrupar a las masas progresistas que llevaron a la presidencia a Ibáñez, optando por el desarrollo de una línea política que se limite a la unidad y colaboración de los partidos populares bajo una política "nacional revolucionaria". Este giro es posible por un diagnóstico que considera agotada la fase de colaboración con partidos centristas o algunos partidos que podrían ser considerados como progresistas, la cual tuvo su primera polémica en el rechazo desde el PSP para participar en el frente cívico, que agrupó a buena parte de la heterogénea oposición al gobierno de Ibáñez juntando al PSCh y al proscrito PC con elementos conservadores y liberales. En este sentido, la lectura del PSP sobre el frente cívico es que "Su acción política se definía (...) como esencialmente defensiva del actual

33 Raúl Ampuero, "El carácter de la revolución chilena", Colección de documentos $N^{\circ} 2$, Prensa Latinoamericana, s/f pp.42-43.

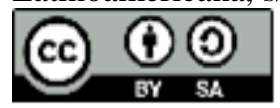


orden burgués y sus formas institucionales, desapareciendo ante esa sacrosanta misión cívica cualquiera otra consideración de índole económica o social..."34

La idea de una política nacional revolucionaria se sustentaba en una lectura que entendía que los fundamentos del problema del estancamiento económico y social del país estaban en la vigencia de los supuestos del sistema capitalista. En este aspecto, la solución al estado de estancamiento general, desde la lectura del PSP, pasaría por acelerar el ritmo de desarrollo, orientándose a satisfacer las necesidades sociales bajo la promoción de un Estado que sea "genuino intérprete" del interés de los trabajadores, el cual sólo puede ser llevado adelante "si se altera la estructura y supuestos ideológicos liberales del actual estado burgués y se construye un Estado Nacional Revolucionario, intérprete confesó de las aspiraciones progresivas de la sociedad, organizador de toda la vida nacional sobre nuevas bases ideológicas de carácter socialista, abandonando todo el lastre de conceptos, actitudes y prejuicios de raíz individualista, que no juegan ningún papel constructivo en las nuevas condiciones sociales" 35 .

En este aspecto, la única forma de instaurar el Estado Nacional Revolucionario es mediante la acción concertada de las clases que por extracción social son progresistas, haciendo necesario "impulsar la agrupación de trabajadores manuales, intelectuales y campesinos en un Frente de Trabajadores comandado por la clase obrera" ${ }^{36}$. La negación de las alianzas con partidos centristas es la profundización de la línea fijada en 1953 y la continuidad a largo plazo de la propuesta de independencia en 1946. De este modo, la burguesía ya no sólo sería incapaz de realizar los cambios propios de la "fase democrática-burguesa", sino que a la luz de los acontecimientos y de la experiencia política del PSP se trataría de una clase siempre regresiva, diagnóstico que se ve agravado por la incapacidad de la clase media de conducir al proletariado por las lógicas del régimen demo burgués. Esta consideración pone fin a cualquier opción intermedia de colaboración con sectores progresistas de la burguesía, pues una política "de alianza de clases entre los trabajadores y la clase pequeño-burguesa ya ha demostrado su absoluta incapacidad para transformarse en fuerza poderosa que haga ceder a la coalición gobernante en concesiones indispensables", y agrega, "no podemos suponer que las clases defensoras de una estructura económica y social del pasado puedan ser las constructoras del devenir (...) Ya no valen las situaciones intermedias" 37 .

De esta forma, la independencia del socialismo popular pasa de la crítica al colaboracionismo producto del fracaso de las experiencias ministeriales al contenido de

\footnotetext{
${ }^{34}$ Aniceto Rodríguez, "Forjando la Unidad Popular. Cuenta política del camarada Aniceto Rodríguez Arenas al Vigésimo Congreso General del PSP", 1955 (Documento inédito mecanografiado, disponible en la colección de la Biblioteca Clodomiro Almeyda). p. 9

35 "La situación económico-social y las tareas de la revolución chilena", Boletín del Comité ejecutivo del PSP, $\mathrm{N}^{\circ} 1$, noviembre de 1955. $\mathrm{p} 2$.

36 "Posición política del PSP acordada en el XVI Congreso ordinario celebrado en Valparaíso recientemente", Diario de sesiones de la cámara de diputados, sesión 12 en 16 de noviembre de 1955

${ }^{37}$ Ídem.
} 
clase, entendiendo que sólo aquellos sectores excluidos poseen la potencialidad política de llevar adelante un proceso de cambio, genuinamente revolucionario, del régimen imperante. De allí la importancia de propiciar acciones unitarias sólo con los partidos y grupos genuinamente representantes de los sectores populares:

En Chile no ha habido nunca una fuerza central rectora que pueda hablar en nombre de la nación, o sea, de sus grandes mayorías ciudadanas. No pudo hacerlo la oligarquía tradicional, porque ella sólo cuidaba sus privilegios de casta; no pudo hacerlo la burguesía, porque se organizó socialmente como cómplice de una realidad oprobiosa; sólo el pueblo mismo, representado por un Partido o un conjunto de partidos auténticamente populares, estará en condiciones de organizar el país en función de los intereses mayoritarios y con un criterio nacional. Esa es la misión histórica que nos incumbe, y para impulsarla los exhortamos a una acción inmediata y sin desmayos, colectiva y unitaria. ${ }^{38}$

La adopción de la línea estratégica del Frente de Trabajadores, posee un contenido marcadamente clasista que tensiona las relaciones con el FRENAP, pero que también, abre la posibilidad de la unidad de los partidos populares. Sin perjuicio de la persistencia en los emplazamientos y debates con el resto de la izquierda, la nueva línea defendida por el PSP "debería expresarse bajo la forma de un Frente de los partidos obreros y la Central Única de Trabajadores, o sea de un 'Frente de Trabajadores' que lleve adelante una política de clase",39, para lo cual "la formación de un bloque a base de los partidos del FRENAP, por un lado, y los Partidos Socialista Popular y Democrático del Pueblo, por otro, es la condición indispensable para salvar al pueblo de los graves peligros que lo amenazan"

En la misma línea, los socialistas populares proponen que ante las opciones políticas de las capas medias, comprometidas con la continuidad del orden imperante y la derecha, empeñada en frenar el ascenso del nivel de vida de las masas, se opone una tercera opción "Progresista y Revolucionaria" que pretende poner el control del estado en las manos de las fuerzas progresistas y al servicio de los intereses de las masas. Una política de este tipo, sólo podría llevarse a cabo con una fuerte organización popular que permitiera la toma del poder y luego la construcción del estado revolucionario, la cual "debe unir en su seno a todas las fuerzas sociales interesadas en la destrucción del régimen y en la construcción de la nueva sociedad" suponiendo "una abierta, amplia y no sectaria movilización de masas" 41

\footnotetext{
${ }^{38}$ Aniceto Rodríguez, op. cit, p.12

39 "Por qué proponemos la política del Frente de Trabajadores", Boletín del Comité ejecutivo del PSP, N², diciembre de 1955. p.1

40 "Una política de clase para poner fin a la ofensiva reaccionaria”, Boletín del Comité ejecutivo del PSP, N³, enero de 1956. p.1

41 "La situación económica y social y las tareas de la revolución chilena", Boletín del Comité ejecutivo del PSP, $\mathrm{N}^{\circ} 1$, noviembre de 1955. p.2
} 
Lo medular del XVI Congreso de Valparaíso en términos ideológicos es la decantación de un diagnóstico que venía gestándose desde mediados de la década del 40 dentro del socialismo chileno. La declaración de independencia y la concepción dinámica y no dogmática del marxismo como "instrumento de interpretación" de la realidad política y social toman forma en la línea estratégica del Frente de Trabajadores. El rechazo del potencial revolucionario de la burguesía nacional proclamada en 1953, la experiencia del giro represivo del gobierno de González en 1948 y la heterogeneidad de las bases de apoyo ibañistas influyen en la posición y diagnóstico socialista de modo indudable: ante el estancamiento del desarrollo nacional producto de la hegemonía de las capas medias, las tendencias regresivas y represivas del gobierno contra el ascendente movimiento popular y la dependencia del capital extranjero se hace necesaria la unidad de las fuerzas progresistas de la clase obrera, campesinos trabajadores manuales e intelectuales en un gran frente de clase, con pretensiones de poder y transformación del estado, sus instituciones y sus lógicas.

El antecedente de esta nueva línea y de la posterior unidad del socialismo y de la izquierda en el Frente de Acción Popular se registra en enero de 1955. Las relaciones entre ambas facciones del socialismo chileno se mantuvieron congeladas hasta esta fecha, cuando el diputado del Partido Agrario Laborista Sergio Recabarren renuncia a su cargo para asumir como ministro del interior del gobierno de Ibáñez. En ese contexto, la heterogénea oposición del frente cívico conformada por los partidos del FRENAP, la Falange Nacional, Socialcristianos, Radicales y Conservadores Unidos se reúne en una mesa redonda con el Socialismo Popular y el Partido Democrático del Pueblo. La intención es levantar una candidatura común en las elecciones fijadas para el 20 de febrero de ese mismo año por el primer distrito de Santiago. Sin embargo, las diferencias se manifestaron rápidamente. Mientras algunos sectores de la mesa dudaban de la calidad opositora del PSP, el Socialismo Popular y el Partido Democrático del Pueblo promovían que el candidato fuera coherente con una línea de izquierda y representante de la unión de los partidos populares ${ }^{42}$.

Las negociaciones y acuerdos sobre la posibilidad de configurar un Bloque Popular que agrupe a las corrientes del socialismo y a los partidos comunista, del trabajo y democrático del pueblo levantaron suspicacias y preocupación en el resto de la oposición, la cual se hace patente luego de que los partidos populares llegaran a un acuerdo "de reagrupamiento de las fuerzas populares democráticas, abordando unidos de inmediato las elecciones extraordinarias", nombrando un comité integrado por un miembro de cada colectividad para coordinar acciones parlamentarias en conjunto ${ }^{43}$. Sin embargo, en forma paralela el gobierno realiza gestiones para que el socialismo popular presente un candidato propio, al que le compromete el apoyo del Partido Agrario Laborista y la posibilidad de volver a formar parte del gabinete. ${ }^{44}$

\footnotetext{
${ }^{42}$ Las noticias de Última Hora, martes 11 de enero de 1955, p.3

${ }^{43}$ Las noticias de Última Hora. Viernes 14 de enero de 1955, p.4

${ }^{44}$ Las noticias de Última Hora. Sábado 15 de enero, p.4
} 
Pese a todo, las negociaciones y la posibilidad de un Bloque Popular que afronte las elecciones extraordinarias se disipan ante la negativa del PSP de proclamar a un candidato que no tenga afinidad ideológica y compromisos doctrinarios concretos para hacer una oposición de izquierda y desde fuera del gobierno. Tampoco ayudan a la acción unitaria la negativa de los partidos del FRENAP para abandonar la posibilidad de un candidato único de "Unidad Nacional", lo cual incluiría, según el PSP a partidos reaccionarios y derechistas que "han colaborado efectivamente en la en la lucha contra el Estado de sitio y las facultades extraordinarias. Sin embargo, todo el país conoce la posición favorable al estado de sitio del Partido Conservador Unido, y la excelente disposición del Partido Liberal a apoyar las facultades extraordinarias, siempre que estas se dirijan contra las tendencias revolucionarias del movimiento obrero..." 45

La oposición de Unidad Nacional termina por designar la candidatura del vicepresidente de la Falange Nacional Rafael Gumucio, mientras que el PSP y el Partido Democrático del Pueblo perseveran en una candidatura del "Bloque Popular", en oposición al gobierno y sin influencia de fuerzas políticas centristas o derechistas. La intención inicial del PSP de no abanderar un candidato propio y más bien sumarse a una candidatura de izquierda intentando dar una señal de unidad termina por derrumbarse, proclamando como candidato a Clodomiro Almeyda, ex ministro del trabajo y de minería de Ibáñez.

Los socialistas defienden la candidatura de Gumucio poniendo énfasis en su rol como opositor al gobierno de Ibáñez y declarando que la oposición de Unidad Nacional "no es un contubernio", defienden también su decisión de participar de una candidatura de Unidad Nacional, declarando que "los socialistas en conciencia sabemos lo que nos une y nos separa dentro de las fuerzas de oposición. Nos separan nuestros planteamientos ideológicos, en lo económico, político y social, pero nos une la defensa del régimen democrático, de las libertades públicas y sindicales" y agregando "estamos unidos también conscientemente en contra de todos los desaciertos del actual régimen" 46 . Por otra parte, el PSP mantiene su oposición y su independencia del ibañismo y de los partidos "derechistas y reaccionarios" como base de la campaña de Almeyda. En este marco, el PSP elabora un manifiesto en apoyo a la candidatura, acusando que con la combinación de la Unidad Nacional "se nos quiere hacer creer que pueden caminar juntos los campesinos expoliados y los latifundistas reaccionarios, los obreros perseguidos y sus patrones capitalistas, los empleados con sueldos de hambre y sus empleadores que especulan, los comunistas con los liberales, los socialistas con los conservadores, los explotados con los explotadores" ${ }^{\text {"47 }}$.

Sin embargo, lo llamativo de la campaña de socialistas populares y democráticos del pueblo es el insistente llamado a la unidad de los partidos de avanzada. Para estos partidos aún era posible rescatar desde un bloque popular los aspectos programáticos del movimiento septembrista que fueron traicionados por el ibañismo, y que según este diagnóstico,

\footnotetext{
45 Ídem

${ }^{46}$ Las Noticias de Última Hora. Domingo 30 de enero de 1955. p.4

${ }^{47}$ Las Noticias de Última Hora. Jueves 27 de enero de 1955 
constituyen los elementos movilizadores de las masas. En la lectura del Socialismo Popular para "terminar con la injusticia social y levantar un régimen popular que modifique sustancialmente la economía en beneficio de las masas, es preciso unir políticamente a esa mayoría, evitando que su división sea aprovechada por los pequeños sectores de la reacción" $"$. La invitación a la unidad se vuelve explicita desde el PSP, al declarar su disposición "a cerrar filas en un gran bloque popular, movilizando a las masas por la conquista del poder para instaurar una Republica Democrática de Trabajadores" haciendo para ello "un llamado a todos los partidos de avanzada para sellar esta alianza y formar un frente de lucha contra la oligarquía y el imperialismo"49.

La elección complementaria, marcada por el abstencionismo, le da el triunfo al candidato Falangista apoyado por las combinaciones de Unidad Nacional con el $28 \%$ de los votos. Pese a la derrota el socialismo popular a través de figuras como el propio Clodomiro Almeyda, Belarmino Elgueta y Aniceto Rodríguez sigue propiciando la unidad de los partidos de avanzada, inclusive cuando Salvador Allende, secretario general del PS, insiste en llamar a Almeyda el "candidato del oficialismo". Lo cierto es que la unidad de los Partidos populares ya había logrado grandes avances incluso cuando no fue posible levantar una candidatura unitaria representante de los partidos de avanzada. Las reuniones de la mesa redonda y sobre todo aquellas realizadas exclusivamente entre los partidos populares demostraban que las posiciones del PSP y el PDP tenían recepción y adhesiones de importancia en las bases del PS. Por otro lado, el constante llamado a la unidad del movimiento popular comenzó a tener respuestas desde el propio Allende, quien proponía "estructurar un amplio movimiento popular que tenga por base esencial luchar por la plena independencia económica de Chile" discrepando de la opción clasista al proponer que "la magnitud del reagrupamiento debe alcanzar a vastos sectores nacionales. Me lo imagino de Radicales hasta Frente del Pueblo, pasando por socialcristianos, falangistas y socialistas del trabajo. Por cierto que creo que (...) tendrán un puesto junto a nosotros, las fuerzas populares que estuvieron junto al Sr. Ibáñez, que han comprendido el error que cometieron." 50

Lo interesante de esta elección es que a cuatro años de registrada la última gran escisión del socialismo chileno durante el periodo en cuestión, la coyuntura electoral fue aprovechada para explicitar las intenciones unitarias de los partidos populares, en una alianza política que lograra extensión y contenido de clase, reafirmando las pretensiones de tomar el poder con un frente de partidos populares en conformidad con el diagnóstico y directrices teóricas del PSP. En este punto, las declaraciones de Allende y de otros personeros del PS también son ilustrativas: ante la tesis clasista se opone el interés por formar coaliciones amplias, que alcancen a la mayor cantidad de partidos y movimientos del espectro político, incluso cuando estos sean de extracción burguesa y de corte reformista.

\footnotetext{
48 Ídem.

${ }^{49}$ Ídem.

${ }^{50}$ Las Noticias de Última Hora. Martes 15 de febrero de 1955, p. 3 
En este sentido, y si bien el PSP es el partido que se niega constantemente a colaborar en frentes amplios en función de la línea de independencia, la adopción de la tesis política del Frente de Trabajadores por su contenido eminentemente clasista supone, como piso mínimo, la alianza de los partidos populares en la labor parlamentaria, la lucha electoral y la actuación conjunta en el campo sindical. En este plano, el PSP promueve la fundación del FRAP poniendo como primera condición la composición de clase de la alianza, la cual venía siendo impulsada desde el XV congreso general. De esta forma, en la fundación del Frente de Acción Popular, desde la lectura del PSP, se impone la tesis de unidad bajo la fórmula del Frente de Trabajadores:

En las conversaciones que se iniciaron por indicación de nuestro Partido para llegar a la Unidad Popular y que acaban de culminar en la creación del FRAP, se plantearon dos criterios distintos. Uno, sostenido por los comunistas, pretendía lograr una Unidad amplia entre sectores de la pequeña burguesía y de la burguesía propiamente tal. En este intento incluían entre los partidos populares a aquellos de centro como el Partido Radical y la Falange Nacional. Según el PC, el movimiento de los trabajadores chilenos debe limitarse a impulsar el desarrollo de la Revolución Democrático-Burguesa y, en consecuencia, debe apoyar a los partidos políticos que representan a la burguesía "progresista", como suelen llamarla. Esta política la han simbolizado en el Frente de Liberación Nacional.

Por otra parte, nuestro Partido, cumpliendo los acuerdos del Congreso de Valparaíso, sostuvo la política de Frente de Trabajadores, que se concreta en el aglutinamiento de los partidos genuinamente representantes de la clase trabajadora chilena, dejando al margen de un compromiso permanente a partidos de centro como el PR y la Falange. En esta forma nosotros creamos un poder político de extraordinaria importancia para acciones de fondo en la lucha por la conquista del poder para el pueblo. No aceptamos, por lo tanto, que partidos comprometidos en la defensa del sistema actual integren un movimiento que tiene objetivo principal lograr la transformación de la estructura económica y social del país ${ }^{51}$

La primera elección apenas constituido el FRAP acrecentó el optimismo de los Socialistas Populares en la nueva alianza. En total, el FRAP logra elegir 248 regidores de los cuales 129 corresponden al PSP, alzándose como la cuarta mayoría a nivel nacional. La segunda reunión plenaria de agosto de 1956 estimaba de manera positiva los resultados obtenidos en la campaña municipal, pero reconoce que aún hay mucho potencial por desarrollar bajo la línea clasista del Frente de Trabajadores, considerando que "Fuera de las fronteras partidistas existe una infinita variedad de organizaciones, grupos e iniciativas sin conformación orgánica, que son unidades potenciales de lucha en esta empresa" ${ }^{\text {"52 }}$.

51 "Instrucciones sobre la aplicación del pacto", Boletín del Comité ejecutivo del PSP, N4, febrero de 1956. p.5

52 "Informe del comité ejecutivo a la II Reunión Plenaria", Boletín del Comité ejecutivo del PSP, №9, agosto de 1956. p. 2 
Otro punto de importancia para la unidad de los partidos populares bajo la línea socialista es la realización del XX Congreso del PCUS, el cual es percibido como una oportunidad para que el PCCh revise "el carácter de las tareas planteadas por la realidad chilena de ahora, sin prejuicios y sin servidumbres intelectuales" las cuales "contribuirán poderosamente a fortalecer la acción del pueblo y la clase obrera" ${ }^{\text {"53 }}$. En la lectura del PSP, la nueva línea soviética propicia el desarrollo de una política tendiente a la distensión del enfrentamiento entre el campo socialista y el bloque socialista, que "Implica una doble ventaja: la fuerzas verdaderamente revolucionarias y anti-imperialistas encuentran un campo más propicio a su desarrollo y se hacen más próximas y necesarias las transformaciones internas en el seno de los dos grandes imperios contemporáneos, en el sentido de la integración, en una sociedad de nivel superior, del socialismo y de la democracia",54. Lo anterior, toma aún más sentido en tanto la tesis del Frente de Trabajadores sigue manteniendo la antigua noción de independencia del movimiento obrero y un contenido antiimperialista, que se expresa en la oposición a las influencias políticas externas, sean soviéticas o norteamericanas.

En este contexto, marcado por la unidad de los partidos populares y el nuevo entendimiento entre el PSP y los comunistas, aún seguía pendiente la reunificación del socialismo chileno, dividido desde 1951 en dos facciones defensoras de estrategias y líneas políticas disímiles. Como era de suponer, los intentos por concretar la reunificación resultaron problemáticos desde un inicio: mientras el PSP proponía la unificación manteniendo las formulaciones teóricas y estratégicas del Frente de Trabajadores, el PSCh pensaba en una negociación que permitiera la convivencia de ambas tendencias bajo el mismo partido. Ante esta última opción el propio Raúl Ampuero en una carta de respuesta a Salvador Allende, entonces secretario general del PSCh, declaraba que de mantener dos tendencias dentro de la colectividad "se volverían a plantear las diferencias teóricas y prácticas superficialmente abordadas en nuestras conversaciones" se presentaría "inevitablemente el dilema: o una fórmula de compromiso con todos los inconvenientes arriba señalados, o una nueva ruptura..." ${ }^{, 55}$, posición que fue ratificada por el último pleno del PSP antes del Congreso de la Unidad:

El reconocer validez y plena vigencia a la política de Frente de Trabajadores implica la seria voluntad e intransigencia de insistir en lo que el PSP cree debe ser la línea fundamental del socialismo en Chile. De ahí que, sustentar y defender la política que el PSP ha venido sosteniendo y defienden en todas las esferas sus militantes, debe ser propósito de todos los miembros del PSP, especialmente valedero si se trata de hacer confluir

\footnotetext{
${ }^{53}$ Ibíd. p. 6.

${ }^{54}$ Ibíd. p.5.

55 "Respuesta del C. Raúl Ampuero al Secretario General del PSCH”, Boletín del comité ejecutivo del PSP, $\mathrm{N}^{\circ} 13$, diciembre de 1956. p. 5
} 
todos los esfuerzos socialistas y conformar una unidad que debe trasuntarse especialmente en lo ideológico ${ }^{56}$

Finalmente, en el mes de julio de 1957 se realiza el XVII Congreso General Ordinario, el que a la postre termina por sellar la reunificación del socialismo chileno. El congreso presenta una tesis política que da continuidad al desarrollo ideológico del socialismo popular, en este aspecto se mantienen las caracterizaciones de la realidad chilena, destacando la condición de país dependiente y estancado en el ámbito político, económico y social. Manteniendo el proyecto de un Estado Nacional Revolucionario y sobre todo la "ineptitud histórica de la burguesía chilena para promover nuestro desarrollo económico, por su debilidad orgánica, su carencia de empuje renovador, su alianza con el imperialismo y la oligarquía, su tendencia al monopolio y su dependencia de la acción y recursos del Estado"57. Siguiendo esta línea, la misma tesis declara el divorcio total entre las aspiraciones populares y los partidos de centro, particularmente el radicalismo.

El voto político aprobado por aclamación y preparado por Julio César Jobet declaraba "Que los partidos Conservador y liberal, y sus apéndices, expresan los intereses de la feudoburguesía ligada al imperialismo; que los partidos Agrario Laborista y Demócrata-Cristiano expresan Intereses de la burguesía agraria e industrial y de algunos sectores medios, ligados al Imperialismo y al Vaticano" y agrega "Que el radicalismo es un partido centrista, socialmente híbrido. En su masa de afiliados y en su dirección predominan los elementos pequeñoburgueses, pero, a la vez, en ambas, bases y directivas, abundan los elementos acaudalados, terratenientes y grandes industriales.... ${ }^{58}$ y por último declara la política del Frente de Trabajadores como "Justa expresión de la unidad del socialismo y del movimiento obrero, eliminando todo compromiso contrario a esta posición" "59. De esta manera, el PSP al menos en el plano de la organización, logra la proclamación de su línea estratégica y la continuidad de la reflexión ideológica iniciada a partir de 1946. Sin embargo, y pese a la sanción de la línea "revolucionaria" la facción de Allende seguirá empeñada en sostener posiciones de acercamiento con el centro y los sectores progresistas, dando forma a las dos tendencias predominantes del ahora unificado Partido Socialista de Chile hasta 1973.

\section{Consideraciones finales}

Hasta aquí, este trabajo postula que la política del Frente de Trabajadores aparece como resultado del desarrollo político y de la reflexión ideológica del socialismo chileno. En este aspecto, la línea estratégica sancionada por el PSP en 1955 y luego por el socialismo unificado, es la síntesis de un desarrollo continuo que se inicia a partir de dos hechos

\footnotetext{
56 "Las importantes resoluciones del pleno del PSP". Boletín del Comité Ejecutivo del PSP, $\mathrm{N}^{\circ} 17$, mayo de 1957. p.2

${ }^{57}$ Tesis política, sindical y organizativa aprobadas por Congreso de la unidad socialista, Santiago, julio de 1957. p. 9

${ }^{58}$ Julio Cesar Jobet, op. cit, p.34

${ }^{59}$ Ídem. P.36
} 
fundamentales: el X Congreso General Ordinario realizado en 1946, donde se impone la "línea revolucionaria", y la Conferencia Nacional del Programa realizada en 1947, que además de definir líneas programáticas, caracteriza el proceso de reflexión, discusión y teorización ideológica del socialismo chileno como uno particularmente inventivo e innovador. Ambos hechos marcan el inicio de una trayectoria ideológica particular que busca justamente rescatar la independencia política y estratégica del partido, además de marcar el rumbo en la elaboración de un programa que, basado en una lectura propia del marxismo, se cristaliza en función de los hechos y la trayectoria política del Socialismo chileno a partir de ese momento, y en particular, del PSP como continuismo de la estructura partidaria que inició este proceso de reflexión.

La línea del Frente de Trabajadores, en este sentido, es producto del desarrollo continuo de la línea política de independencia partidaria aprobada en 1946 y sustentada por el programa de 1947, la cual está determinada en su desarrollo ideológico por la experiencia partidaria de colaboración, crítica, discusión y faccionalismo que caracterizaron al socialismo chileno durante el periodo. De esta forma, la trayectoria ideológica de la línea socialista aparece como un constructo teórico particular, con una trayectoria de desarrollo propio que propone, en función de la crítica a la experiencia colaboracionista, una política de clase para la disputa y conquista del poder. En este aspecto, la tesis del Frente de Trabajadores es esencialmente unitaria y clasista, entiende que solo los sectores de extracción social obrera y proletaria son capaces de llevar adelante las transformaciones estructurales que permitan construir el socialismo, rechazando por completo la tesis de la revolución democráticoburguesa. Lo anterior obedece a un diagnóstico que toma fuerza a partir de 1953 y que postula la imposibilidad de la burguesía y de las clases medias de realizar la fase democrática burguesa de la revolución, lo anterior parte de la constatación de una burguesía aliada al imperialismo y sustentada en la propiedad del latifundio, por lo tanto, propia de una estructura económica que se percibía como semicolonial y semifeudal en un contexto general de atraso económico, social y también político en Chile.

Considerando lo anterior, ¿Es posible hablar de una ideología propiamente socialista? Al menos en términos teóricos se debe reconocer la posibilidad que tienen los actores (líderes, dirigentes, intelectuales, etc) de elaborar diagnósticos y definir líneas de acción que obedezcan a lecturas y posiciones teóricas particulares sobre la realidad en la cual están insertos. El pensamiento político, desde esta perspectiva, es radicalmente histórico en tanto su contexto de producción y desarrollo es determinante para la comprensión del mismo. En este sentido, el socialismo chileno produce diagnósticos que recogen la experiencia política y social del partido, los que sirven como bases para la producción teórica desde una posición doctrinaria novedosa respecto del marxismo. Lo anterior, deriva en un diagnóstico que en términos generales niega el potencial revolucionario de los sectores burgueses asignando un papel preponderante a los "trabajadores manuales, intelectuales y campesinos" para el derrumbe de un régimen "oligárquico, semi feudal y semi colonial" que permita dar paso a una República Democrática de Trabajadores. 
En resumen la política del Frente de Trabajadores adoptada en 1955, en tanto estrategia que propone la unidad entre partidos populares como forma para afrontar la disputa por el poder, es resultado de la discusión y debate ideológico en el seno del socialismo chileno, el cual recoge las experiencias de las crisis partidarias de la década del 40, la reflexión y crítica surgida a propósito de la colaboración socialista y socialista popular en coaliciones y gobiernos de coalición, además de la adopción de posiciones doctrinarias particulares que son propias del socialismo chileno a partir de 1947, las cuales son profundizadas y puestas a disposición de la actividad teórico partidaria por el PSP. Sin embargo, lo anterior no niega la existencia de discusiones entre el PSP con el resto de partidos, grupos y movimientos políticos y mucho menos la importancia de estas en la trayectoria ideológica del socialismo chileno, por el contrario, las discusiones y debates con el resto de la izquierda son determinantes en la trayectoria ideológica y política del socialismo desde la década de 1940, influyendo en las posiciones inconformistas durante el Frente Popular, la línea tercer frentista y de independencia, la proclamación de Ibáñez como candidato presidencial y la promoción de la "unidad popular" a partir de 1955.

Estas discusiones son expresión de las diferencias doctrinarias existentes dentro de la izquierda, las cuales tienen su manifestación más evidente en el debate entre el PSP y el PSCh hasta 1957, y en el constante desacuerdo entre socialistas y comunistas hasta la colaboración definitiva a partir de la fundación del Frente de Acción Popular en 1956, instancias que si bien permitieron la unidad de acción de los partidos populares en ningún caso lograron poner fin a las divergencias entre los mismos. En términos teórico-políticos hay dos formas de entender dichas divergencias:

1) Como un desacuerdo respecto de las estrategias de alianzas para afrontar la competencia por el poder, donde se debate la opción defendida por el PC y el PSCh que desde 1952 propone formar un frente amplio que incluya sectores de la burguesía progresista y partidos de centro como el Radical y la Falange, y por otro lado, la propuesta del socialismo popular y el Partido Democrático del Pueblo consistente en una gran alianza de partidos obreros y populares con fuerte presencia en el movimiento sindical y cerrado a la opción de coaliciones con elementos de la burguesía y los partidos de centro, por considerar que son fuerzas siempre regresivas.

2) Como una diferencia en las posiciones ideológicas, donde las diferentes lecturas de la realidad chilena desde la teoría marxista son fundamentales para comprender las divergencias entre las posiciones del PSP y aquellas defendidas por el PC. A partir de 1953 el desencuentro "teórico" toma forma con la cuenta de Raúl Ampuero al congreso del PSP al negar, para el caso chileno, la posibilidad de que exista una fase demoburguesa en el proceso revolucionario nacional. Esta cuenta marca el inicio de una divergencia que caracterizará las relaciones entre la tesis del Frente de liberación nacional propuesta por el PC y el Frente de Trabajadores defendido por el socialismo, divergencias que son también claves para la comprensión del trasfondo ideológico y doctrinario del debate estratégico dentro de la izquierda durante el periodo que aborda este trabajo. 
Justamente en este segundo punto es donde se ha desarrollado, al menos parcialmente, este trabajo. El examen de una parte de la trayectoria ideológica del Frente de Trabajadores implica dar cuenta de un fenómeno aún poco abordado por la historiografía y las ciencias sociales en general, que implica reconocer el peso de las ideas y las elaboraciones teóricas en las estrategias y posiciones políticas más prácticas, lo cual para el caso del PSP implica la adopción de una lectura particular del marxismo, la elaboración de diagnósticos en función de dicha lectura y la proclamación de estrategias y líneas políticas fundamentadas en lo anterior. De esta manera, las ideas y la ideología no pueden ser comprendidas si no es en función de las prácticas y líneas políticas concretas que inspiran.

\section{Bibliografía}

\section{Publicaciones periódicas}

Boletines del comité ejecutivo del PSP

Revista Espartaco (segunda época)

Diario de sesiones de la cámara de Diputados

Diario de sesiones del Senado

Las Noticias de Última Hora

\section{Fuentes primarias}

- Aniceto Rodríguez, "Forjando la Unidad Popular. Cuenta política del camarada Aniceto Rodríguez Arenas al Vigésimo Congreso General del PSP", 1955 (Documento inédito mecanografiado, disponible en la colección de la biblioteca Clodomiro Almeyda).

- Brigada de Profesionales, Tesis política, sindical y organizativa aprobadas por Congreso de la unidad socialista, Santiago, julio de 1957.

- Cesar Godoy, ¿Qué es el inconformismo?, Santiago, Editorial Combate, 1940.

- Comité nacional de Unidad del Socialismo, Unidad, doctrina y acción del socialismo, Santiago, Impresora Rosas, 1949.

- Julio Cesar Jobet, El Partido socialista de Chile (II Tomos), Santiago, Ediciones Prensa Latinoamericana, 1971.

- Julio Cesar Jobet, El socialismo chileno a través de sus congresos, Santiago, Ediciones Prensa Latinoamericana, 1965.

- Partido Socialista de Chile, El Partido Socialista y su $6^{\circ}$ Congreso Ordinario, Talleres Gráficos Gutenberg, 1940.

- Partido Socialista de Chile, Manifiesto que dirige el Partido Socialista al país, Santiago, Editorial Cultura, enero de 1940.

- Partido Socialista de Chile, Por una democracia de trabajadores. Programa del Partido Socialista, Santiago, imprenta victoria, 1948.

- Partido Socialista de Chile, Colección de documentos $N^{\circ} 2$, Santiago, Prensa Latinoamericana, s/f.

- Oscar Waiss, Nacionalismo y Socialismo en América Latina ( $2^{\circ}$ edición), Buenos Aires, Iguazú, 1961. 


\section{Fuentes secundarias}

- Benny Pollack, "The Chilean Socialist Party: Prolegomena to its Ideology and Organization", Journal of Latin American Studies 79:1, 1978.

- Benny Pollack y Herman Rosenkrantz, Revolutionary Social Democracy: The Chilean Socialist Party, London, Pinter, 1986.

- David Corkill, "The Chilean Socialist Party and the Popular Front. 1933-1941”, Journal of Contemporany History, 11:2/3, julio 1976, 261-273.

Fernando Casanueva y Manuel Fernández, El Partido Socialista y la lucha de clases en Chile, Santiago, Quimantu, 1973.

- JGA. Pocock, Pensamiento político e historia: Ensayos sobre teoría y método, Madrid, Ediciones Akal, 2009.

- Joaquín Fernández Abara, El ibañismo (1937-1952): un caso de populismo en la política chilena, Santiago, Instituto de Historia Universidad Católica de Chile, 2007.

- Luis Ortega, "La radicalización de los socialistas de Chile en la década de 1960", Universum 2008, 23:2, 2008. 152-164.

- Marcelo Casals, El alba de una revolución. La izquierda y la construcción estratégica de la "vía chilena al socialismo". 1956-1970, Santiago, Lom, 2010

Paul Drake, Socialismo y Populismo. Chile 1936-1973, Instituto de Historia Universidad Católica de Valparaíso, 1992.

- T. Ball, J. Farr, \& R. L. Hanson (Eds.), Ideas in context: political innovation and conceptual change, Melbourne, Cambridge university press, 1995.

William E. Connolly, The Terms of Political Discourse. Nueva Jersey, Princeton University Press, 1993. 